\title{
Study on the Control Strategy of In-Wheel Driven Electric Vehicle Yuefeng Lei
}

\author{
School of Hyundai Automobile, Rizhao Polytechnic, Rizhao, China \\ Ishjff@126.com
}

Keywords: In-wheel driven; Electric vehicle; High-speed motorized spindle; Control strategy

\begin{abstract}
The in-wheel driven electric vehicle is a kind of electric vehicle with special electric drive structure. It uses four independent wheel hub motors in the drive wheel to drive the motion of the vehicle. In this paper, an optimization algorithm is applied to this drive structure and a closed-loop control system is formed. Through the control system designed in this paper, the driving wheel can be controlled individually or wholly, so that the greater potential for improving the power performance, stability and safety of the vehicle can be provided. The simulation results show that this method has a good optimization effect and the system is stable.
\end{abstract}

\section{Introduction}

At present, among a wide range of the electric vehicle technical selections, wheel motor drive electric vehicle has become a new direction and it has gained lots of attentions from academia and engineers. In China, the research on wheel motor drive electric vehicle is in the initial stage. But because of its unique advantages, wheel motor drive electric vehicle will have broad prospects for application.

\section{The Dynamic Mathematical Model}

The HEV model structure is shown in Figure 1.

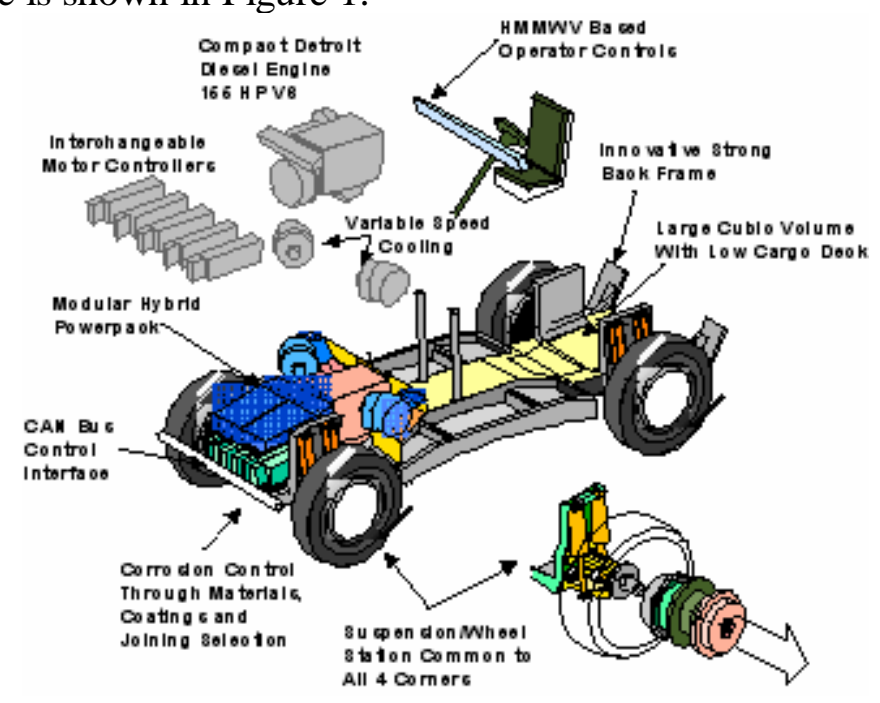

Figure 1. HEV model structure

The key technologies of the wheel driven electric vehicle include the following aspects.

Electronic Differential Control. The front wheel is turned through mechanical differential speed, and the rear wheel adopts electronic differential steering control.

Motor Vehicle. In order to make the electric vehicle have good performance, the drive motor (electric wheel) should have a wide speed range, high speed and large enough starting torque. At the same time, it should have small volume, light weight, high efficiency and better energy feedback performance. 
Motor Drive Technology. The core of realizing wheel drive is motor drive and control technology, including vehicle stability control, system dynamic performance optimization and energy saving control.

The dynamic mathematical model of high-speed motorized spindle can be expressed as

$$
\left\{\begin{array}{l}
\dot{x}_{1}=f_{1}\left(x_{1}\right)+b_{1}\left(x_{1}\right) x_{2} \\
\dot{x}_{2}=f_{2}\left(x_{1}, x_{2}\right)+b_{2} u
\end{array}\right.
$$

The error state vector $\mathrm{e} 1, \mathrm{e} 2 \in \mathrm{R} 2$,

$$
\left\{\begin{array}{l}
e_{1}=x_{1}-x_{1 d} \\
e_{2}=x_{2}-x_{2 d}
\end{array}\right.
$$

where $x_{1 d}, x_{2 d}$ are desired state trajectory of the system, the tracking error dynamics derived from Eq. 1 and Eq. 2 can be obtained as follows

$$
\left\{\begin{array}{l}
\dot{e}_{1}=f_{1}\left(x_{1}\right)+b_{1}\left(x_{1}\right) x_{2}-\dot{x}_{1 d} \\
\dot{e}_{2}=f_{2}\left(x_{1}, x_{2}\right)+b_{2} u-\dot{x}_{2 d}
\end{array}\right.
$$

Various parameters updating laws of the improved RBF neural network are supposed

$$
\begin{aligned}
& \dot{\hat{W}}_{1}=-\Gamma_{W_{1}}\left(\hat{\phi}_{1}-\hat{\phi}_{1 u}^{\prime} * \hat{\mu}_{1}-\hat{\phi}_{1 \sigma}^{\prime} * \hat{\sigma}_{1}\right) e_{1}^{\mathrm{T}}-\Gamma_{W_{1}} \delta_{W_{1}} \hat{W}_{1} \\
& \dot{\hat{\mu}}_{1 i}=-\Gamma_{1 \mu} \hat{\phi}_{1 u_{i}}^{\prime}\left(\hat{W}_{1} e_{1}\right)_{i}-\Gamma_{1 \mu} \delta_{1 \mu} \hat{\mu}_{1 i} \\
& \dot{\hat{\sigma}}_{1 i}=-\Gamma_{1 \sigma} \hat{\phi}_{1 \sigma_{i}}^{\prime}\left(\hat{W}_{1} e_{1}\right)_{i}-\Gamma_{1 \sigma} \delta_{1 \sigma} \hat{\sigma}_{1 i}
\end{aligned}
$$

\section{The Adaptive Backstepping Control System}

The establishment of system simulation module as shown in Figure 2 in MATLAB/Simulink.

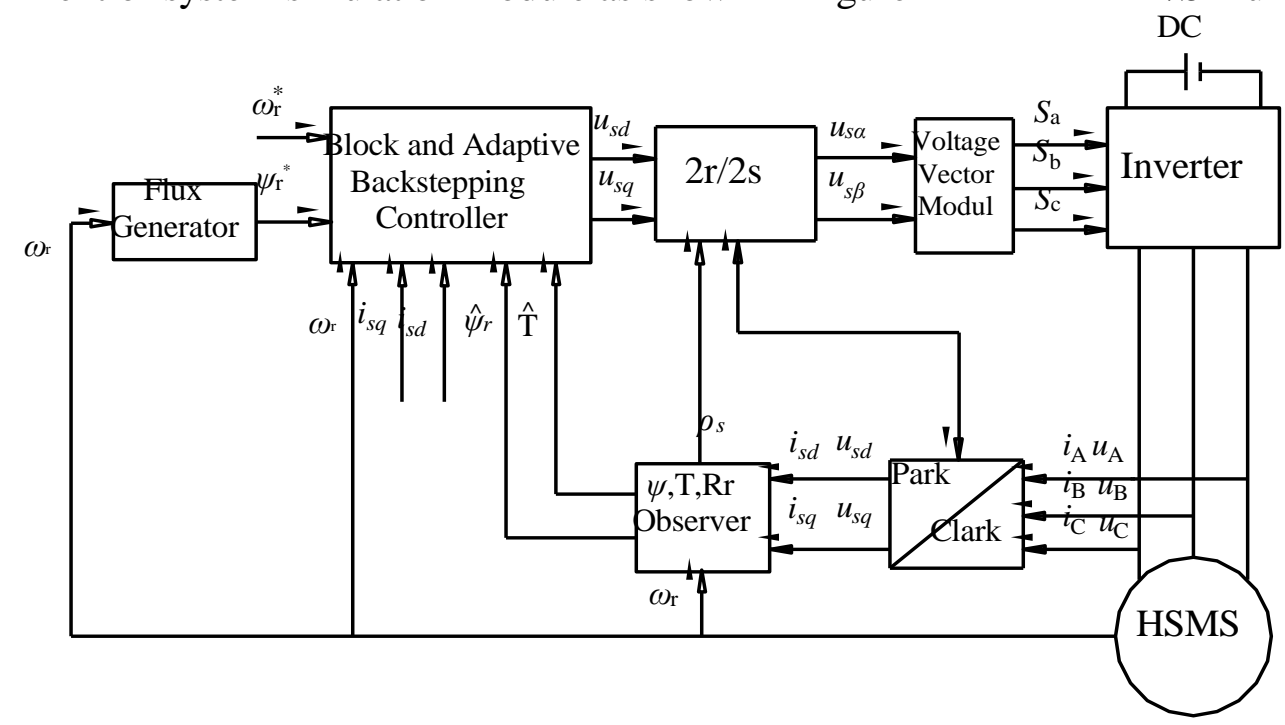

Figure 2. Functional block diagram of proposed motorized spindle's block adaptive backstepping control system

To verify the effectiveness of adaptive block backstepping control for the proposed motorized spindle and the rationality of using the original parameters of asynchronous electric spindle system is shown in Table 1. 
Table 1 High-speed motorized spindle data of type 170MD20Y20

\begin{tabular}{|c|c|c|c|}
\hline Parameter & Values & Parameter & Values \\
\hline Rated voltage & $350 \mathrm{~V}$ & Rotor resistance & $0.21 \Omega$ \\
\hline Rated current & $46 \mathrm{~A}$ & Stator resistance & $0.11 \Omega$ \\
\hline Rated power & $20 \mathrm{~kW}$ & Stator inductance & $0.00030 \mathrm{H}$ \\
\hline Rated speed & $20000 \mathrm{rpm}$ & Rotor inductance & $0.00031 \mathrm{H}$ \\
\hline Pole-pairs & 2 & Mutual inductance & $0.01017 \mathrm{H}$ \\
\hline
\end{tabular}

\section{Simulation}

Speed response of motorized spindle under block and adaptive backstepping control strategy is shown in Figure 3.

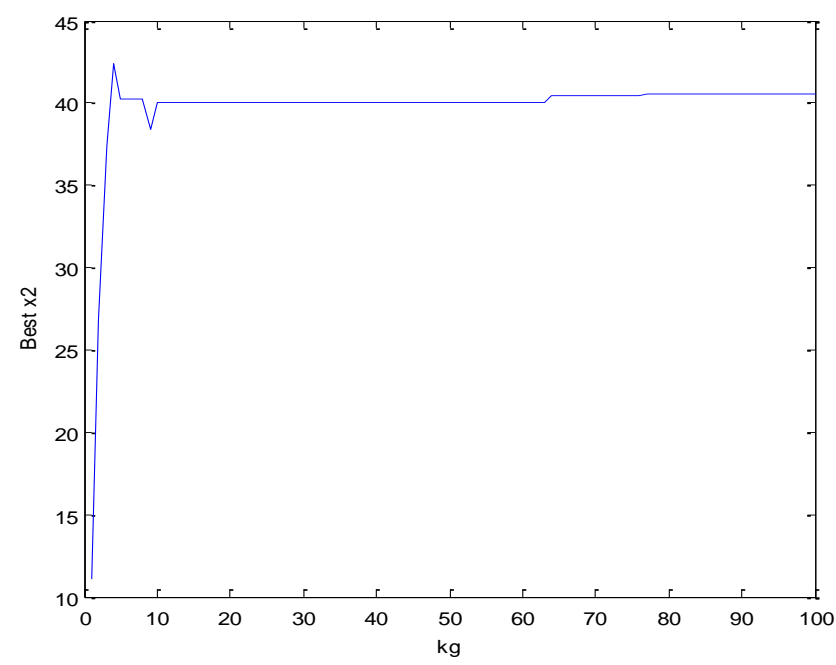

Figure 3. Speed response of motorized spindle under block and adaptive backstepping control strategy

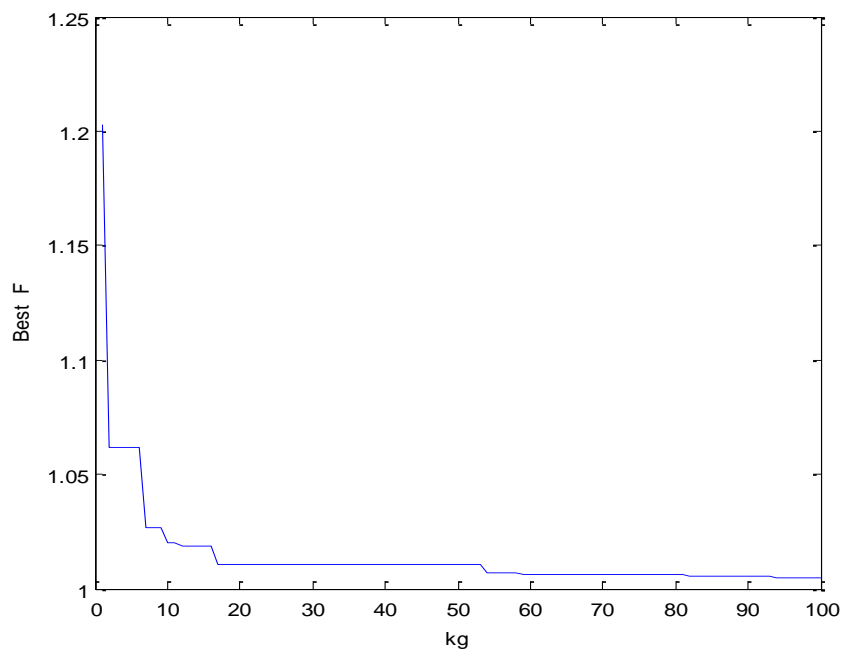

Figure 4. Torque response of the high-speed motorized spindle under block and adaptive backstepping control system 
The regression test is shown in Figure 5.
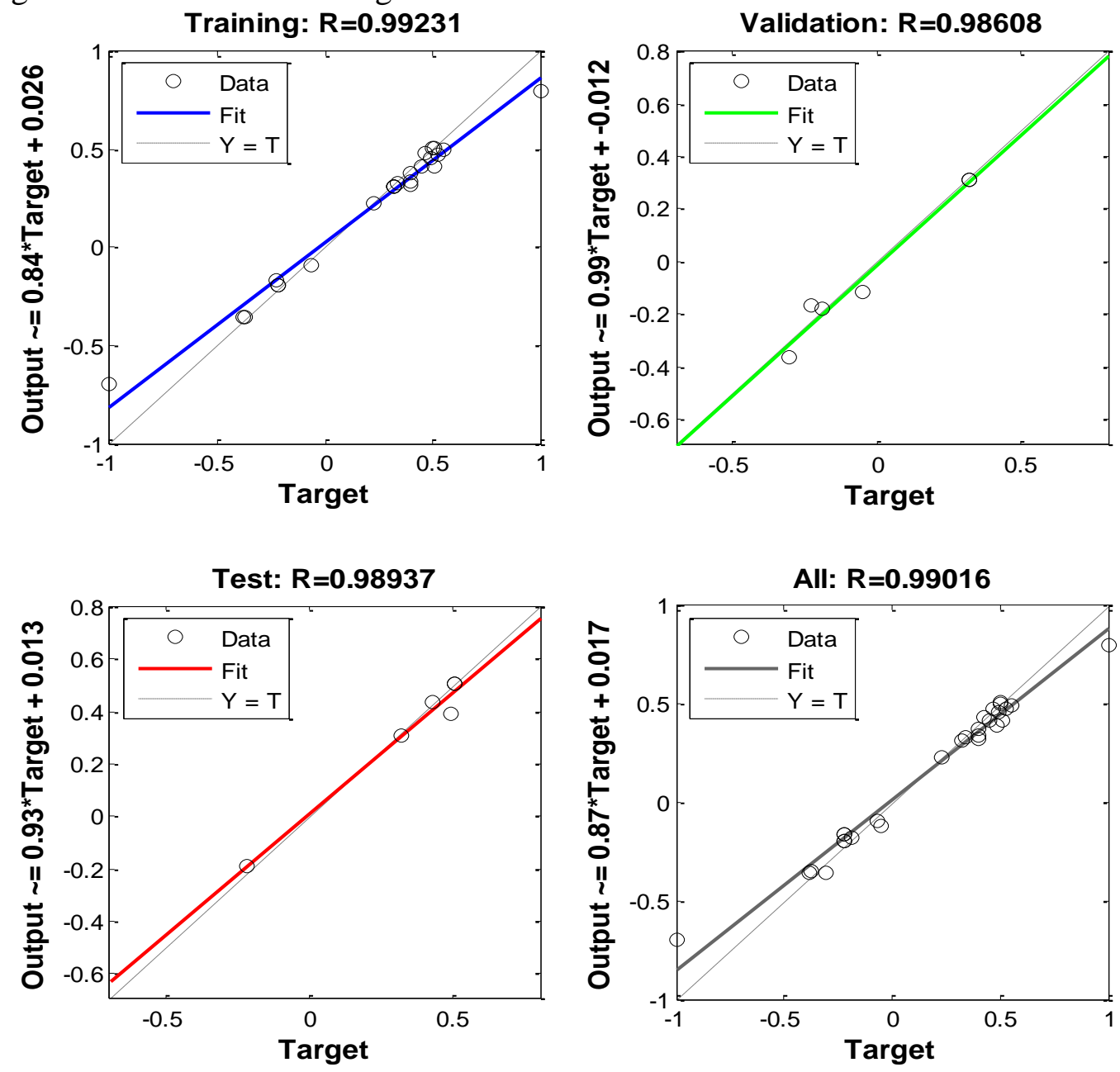

Figure 5. Regression test

\section{Summary}

In this paper, the drive performance of wheel motor drive electric vehicle was theoretically discussed and analyzed by simulation. Some qualitative conclusions were obtained and they can be the references for the future in-depth research.

\section{References}

[1] E. Abele, Y. Altintas, and C. Brecher. Machine tool spindle units, Manufacturing Technology, 59 (2012), 781-802.

[2] FJ Lin and CC Lee. Adaptive backstepping control for linear induction motor drive to track periodic references, Electric Power Applications, 147 (2013), 449-458.

[3] E Vahabli, and S Rahmati, Application of an RBF neural network for FDM parts' surface roughness prediction for enhancing surface quality, International Journal of Precision Engineering \& Manufacturing, 17 (2016) , 1589-1603.

[4] D. Traoré, J. De Leon, and A. Glumineau. Adaptive interconnected observer-based backstepping control design for sensorless induction motor, Automatica, 48 (2012), 682-687. 